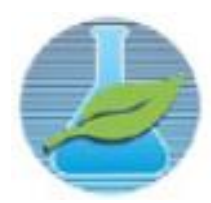

$\mathrm{JCEC} / \mathrm{REQ}^{2}$

Journal

ISSN: 2446-9416

"EU, A INDÚSTRIA E O MUNDO"

08 a 11 de novembro de 2016 no campus Viçosa da UFV

Departamento de Engenharia de Produção e Mecânica - DEP

Universidade Federal de Viçosa - UFV

\title{
AVALIAÇÃO DO SISTEMA DE SUSPENSÃO "SEMI-TRAILING ARM" PARA APLICAÇÃO EM VEÍCULOS OFF-ROAD TIPO BAJA
}

\author{
Lucas de Carvalho Santana, Geice Paula Villibor \\ Universidade Federal de Viçosa, Departamento de Engenharia de Produção e Mecânica \\ Avenida Peter Henry Rolfs, s/n - 36570-000 - Viçosa - Minas Gerais \\ ${ }^{1}$ lucas.c.santana@ufv.br, ${ }^{2}$ geice.villibor@ufv.br
}

\section{INTRODUÇÃO}

A Sociedade de Engenheiros da Mobilidade (SAE) é uma entidade sem fins lucrativos que congrega pessoas físicas (engenheiros, técnicos e executivos) unidas pela missão comum de disseminar técnicas e conhecimentos relativos à tecnologia da mobilidade. Desde 1995, a SAE Brasil realiza, todos os anos, uma competição de engenharia para estimular estudantes a projetarem veículos de competição off-road do tipo baja. Criada em 2008, a equipe da Universidade Federal de Viçosa, tem trabalhado continuamente no projeto de seu protótipo e a atividade tem propiciado aos estudantes uma experiência única na área de projeto automobilístico.

Durante a competição, o protótipo projetado e construído pelos estudantes é submetido a diferentes provas das quais se podem citar as provas de conforto e o enduro de resistência. Os sistemas de suspensão são mecanismos que exercem papel fundamental na dinâmica veicular, atuando diretamente no comportamento da carroceria do veículo. Especificamente no veículo baja, os principais objetivos são: absorver qualquer tipo de irregularidade da pista, preservando os outros subsistemas contra esforços indesejados, melhorar o conforto do piloto e proporcionar melhores condições de contato entre pneu e solo.

A análise e o estudo aprofundado do sistema de suspensão permitem determinar a intensidade, duração e características das cargas dinâmicas atuantes em diferentes cenários de funcionamento e conhecer as cargas reais atuantes. Nesse contexto, supõe-se que ao estudar a dinâmica do sistema de suspensão seja possível propor um modelo de suspensão mais confortável, seguro e com melhor desempenho para o veículo.

\section{OBJETIVO}

Avaliar o conceito de uma suspensão do tipo "Semi-trailing Arm" e identificar as vantagens e desvantagens que o modelo proposto possa oferecer quando aplicado em veículos off-road tipo baja, de modo a torná-lo mais competitivo.

\section{MATERIAIS E MÉTODOS}

Neste item serão apresentadas as etapas e a metodologia utilizada para avaliar o conceito da suspensão Semi-Trailing Arm a fim de alcançar o objetivo proposto no trabalho. Inicialmente, será feito um estudo um pouco mais profundo do sistema em questão, para que então se torne possível seguir com a análise identificando as cargas e os componentes sujeitos aos maiores esforços.

\subsection{O modelo em questão}


Trata-se, portanto de uma suspensão do tipo independente que permite o movimento das rodas separadamente. Porém, para que se possa compreender melhor o sistema com o qual se está trabalhando é interessante fazer, primeiro, uma análise minuciosa do mesmo, levando em consideração cada componente físico necessário para o funcionamento, assim como o processo de fabricação e montagem de cada um deles. Portanto, a seguir, prossegue-se o detalhamento de tais itens.

\subsubsection{Partes componentes}

Basicamente, compõem o sistema:

- Suportes para fixação na carroceria do veículo

- Braço de controle ou bandeja

- Conjunto mola/amortecedor

- Semi-eixo de roda

- Rolamento

- Buchas de suspensão

- Cubo de roda

\subsubsection{Materiais e processo de fabricação}

Os materiais empregados na confecção das peças que integram o conjunto, geralmente, envolvem aços carbono de alta resistência, como o SAE 4130 e SAE 4340, ligas de alumínio de maior resistência (linha naval), ferro fundido e aço forjado.

\subsubsection{Montagem}

A principal característica do sistema Semi Trailing Arm está no posicionamento angulado conferido aos braços de controle durante a etapa de montagem (que, obviamente, requer adaptações no processo de construção). Simplificadamente são dois ângulos que definem a posição do braço de suspensão, geralmente denominados " $\alpha$ " e " $\beta$ ".

\subsection{Dinâmica do sistema}

A inclusão dos ângulos $\alpha$ e $\beta$ nos processos de fabricação e montagem, que caracterizam uma suspensão como sendo do tipo Semi-Trailing Arm, afetam diretamente o comportamento dinâmico do conjunto e por isso exigem muita atenção ao serem quantificados. Diz-se que o sistema é híbrido por possuir características semelhantes aos modelos Trailing Arm e Swing Axle, porém apresenta muito mais características "trail" do que "swing", ou seja, mais "arrasto" que "oscilação" por haver maior variação de convergência/divergência se comparado às variações de cambagem.

\subsection{Esforços solicitantes}

Uma das vantagens das suspensões do tipo Semi-Trailing Arm é o reduzido número de componentes que compõem seu conjunto, liberando assim espaço para outros subsistemas do veículo. Porém, suspensões cujo layout é simplificado como a própria Semi-Trailing, Trailing Arm, Swing Axle, etc. tendem a expor seus elementos estruturais a constantes e intensos esforços, justamente por não ter para onde direcionar as cargas atuantes no sistema. Isso faz com que os engenheiros sejam obrigados a projetar peças mais robustas, de forma a aumentar sua resistência.

\section{ANÁLISE E RESULTADOS}

Após serem avaliadas todas as características da suspensão Semi-Trailing Arm, levando em consideração suas vantagens e desvantagens, custo de fabricação e manutenção e desempenho proporcionado ao carro, propôs-se um modelo que pudesse ser aplicado ao veículo baja. A geometria e os respectivos componentes que definem esse modelo estão ilustrados na Fig. 1. 


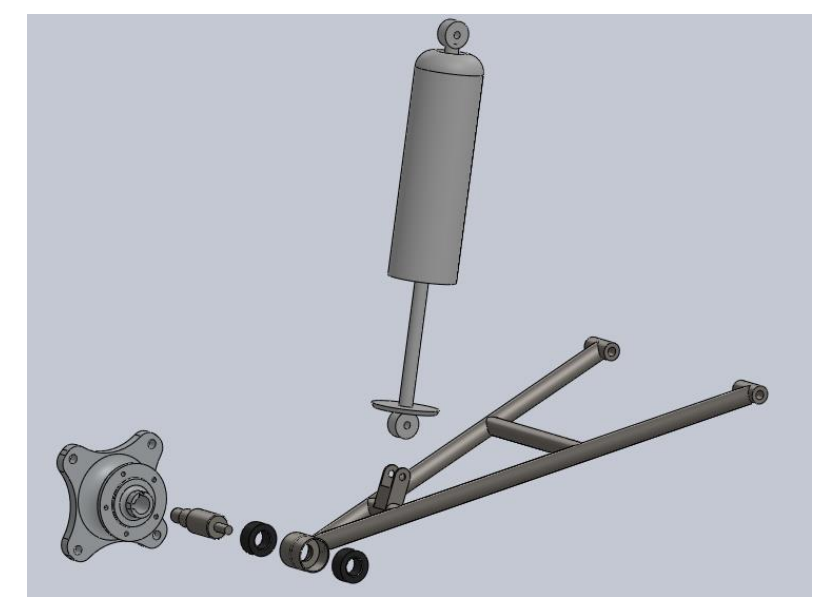

Figura 1 - Modelo proposto ao veículo UFVbaja.

Além do bom comportamento dinâmico, o tipo de suspensão é ideal para a traseira de um baja porque possui geometria simples e libera bastante espaço para motor e transmissão, que em geral, ficam apertados na parte de trás do carro. Facilita, também, a manutenção, já que se tem o acesso praticamente livre a esses subsistemas graças ao reduzido número de componentes da suspensão.

\section{CONCLUSÃO}

No presente trabalho foi realizada uma avaliação completa do sistema de suspensão SemiTrailing Arm com enfoque para aplicação em veículos off-road tipo baja. Através do estudo pode-se concluir que o modelo em questão confere ao carro características que compatibilizam com a proposta do mesmo, adequando-o aos requisitos que são solicitados a ele. Isso inclui boa manobrabilidade (capacidade em realizar curvas de pequeno raio), robustez, baixo custo de produção e manutenção entre outros. Dessa forma foi possível propor uma configuração que pudesse ser aplicada ao veículo da equipe UFVbaja, de modo a torná-lo mais competitivo.

\section{AGRADECIEMTOS}

Os autores agradecem à FAPEMIG pelo apoio financeiro na realização deste projeto de pesquisa (TEC-APQ-03638-14). Agradecemos também à Equipe UFVbaja pelo suporte e apoio tanto técnico como motivacional.

\section{REFERÊNCIAS}

TANIGAVA, Rodrigo K. "Simulação e avaliação das forças na suspensão do veículo ufvbaja para diferentes tipos de manobras". Trabalho de conclusão de curso, Universidade Federal de Viçosa - Viçosa, 2014.

GILLESPIE, T. D. "Fundamentals of Vehicle Dynamics". Society of Automotive Engineers, p. 237247, 1992. 